\title{
Extensive Stroke Associated with Tranexamic Acid Therapy
}

\author{
Fernando Cabrera-Naranjo, Ayoze González-Hernández, Oscar Fabre-Pi, Ana Carolina, \\ López-Veloso, Santiago Díaz-Nicolás, Alberto Cubero-González.
}

Can. J. Neurol. Sci. 2010; 37: 692-693

Stroke in young adults accounts for almost 5-10\% of all acute strokes $^{1}$. Acute ischemic stroke in young adults requires a wide etiological study since it is usually due to infrequent or unusual causes of stroke. Frequently, the association of several prothrombotic conditions, such as prothrombotic drug therapy, increases the risk of acute ischemic stroke in young adults.

\section{Case Report}

A 38-year-old woman was admitted to the hospital because of sudden, right-sided weakness and impaired language expression and comprehension. The patient had a history of tuberculosis ten years prior and of thrombophlebitis in the lower-left limb five months prior. She was taking oral contraceptives. Three weeks before admission she started treatment with daily tranexamic acid (500 mg tid) under gynecological supervision due to onset of active metrorrhagia, but no other risk factors for vascular disease were present.

The patient had been well until the day of admission. The morning of hospital admission the patient had sudden rightsided hemiparesis and impaired language expression and comprehension.

On examination, the mucous membranes were pale. The blood pressure was $110 / 65 \mathrm{~mm} \mathrm{Hg}$, and the pulse 100 beats per minute. The respiratory rate was 14 breaths per minute and oxygen saturation $93 \%$, while she was breathing ambient air. She was not able to follow simple commands, nor to repeat words, name objects or speak at all. The pupils were round and reactive to light and the eyes were conjugately deviated to the left. There was a lack of menace reflex on the right side, a right-side facial droop, a right hemiplegia and a Babinski reflex of the right big toe (National Institute of Health Stroke Scale $=17$ ). The computerized tomography and the cranial magnetic resonance imaging revealed an extensive middle cerebral artery (MCA) infarct (Figure). The administration of intravenous tPA thrombolysis was ruled out because of active metrorrhagia.

The serum levels of electrolytes and the results of renal and liver function tests were normal. Hemoglobin concentration was $7.7 \mathrm{~g} / \mathrm{dL}$. Coagulation parameters were normal. Antinuclear, anti-neutrophil cytoplasmic and anticardiolipin antibodies all were negative. The lupus-anticoagulant was also negative. The proteinogram was normal. The plasmatic homocisteine level was $16.4 \mathrm{umol} / \mathrm{L}$ [4-15 umol/L]. Tumor markers (carcinoembryonic antigen, carbohydrate antigen 19.9, cancer-antigen 125, alpha phetoprotein and $\beta-2$ microglobulin) were normal. The hereditary thrombophilia test, including Factor V Leiden, protein $\mathrm{C}$, protein $\mathrm{S}$ and antithrombin 3, was negative. The eco-Doppler and the magnetic angioresonance studies of supra-aortic branches performed five days after admission were normal, and there was no evidence of left internal carotid artery (L-ICA) dissection. However, the transcranial doppler detected an asymmetric mean velocity profile in both MCAs; the mean velocity value on the left MCA was $170 \mathrm{~cm} / \mathrm{s}$ without air bubble passage. An intracranial arteriography was consequently performed seven days after admission and the results were normal. Chest radiograph showed no abnormalities. Transthoracic echocardiogram and transesophageal echocardiogram reported normal parameters. Abdominal echography showed no evidence of malignant disease.

The patient needed several transfusions of erythrocyte concentrates during admission, because of anaemia due to active metrorrhagia. The patient was discharged 21 days after admission, having no improvement in the National Institute of Health Stroke Scale initial score (17) and a modified Rankin scale of grade 5 .

\section{Discussion}

Strokes in young adults are relatively uncommon. The etiologic and prognostic features that characterize strokes in older persons may not apply to young adults. Besides, the cause of the stroke remains unknown in almost one third of the cases, despite extensive diagnostic investigations ${ }^{2-4}$. For these reasons, a broad diagnostic work-up is needed in order to detect uncommon causes of stroke.

It is widely known that oral contraceptives increase the risk of ischemic stroke. Thus, the use of oral contraceptives is associated with a ninefold increased risk of cerebral infarction in women $^{5}$. This risk is higher in patients with other prothrombotic factors as arterial hypertension or smoking habit. Prothrombotic drugs are widely used in the treatment of metrorrhagia. One of these drugs is tranexamic acid. Tranexamic acid seems to be safe as first-line agent for metrorrhagic conditions; in fact, several

From the Department of Neurology, Hospital Universitario of Gran Canaria Dr. Negrín, Las Palmas de Gran Canaria (Canary Islands - Spain).

Received January 25, 2010. Final Revisions Submitted March 15, 2010. Correspondence to: Ayoze González-Hernández, Department of Neurology (Hospital Universitario de Gran Canaria Dr. Negrín), Barranco de la Ballena s/n, 35020 Las Palmas (Canary Islands - Spain). 


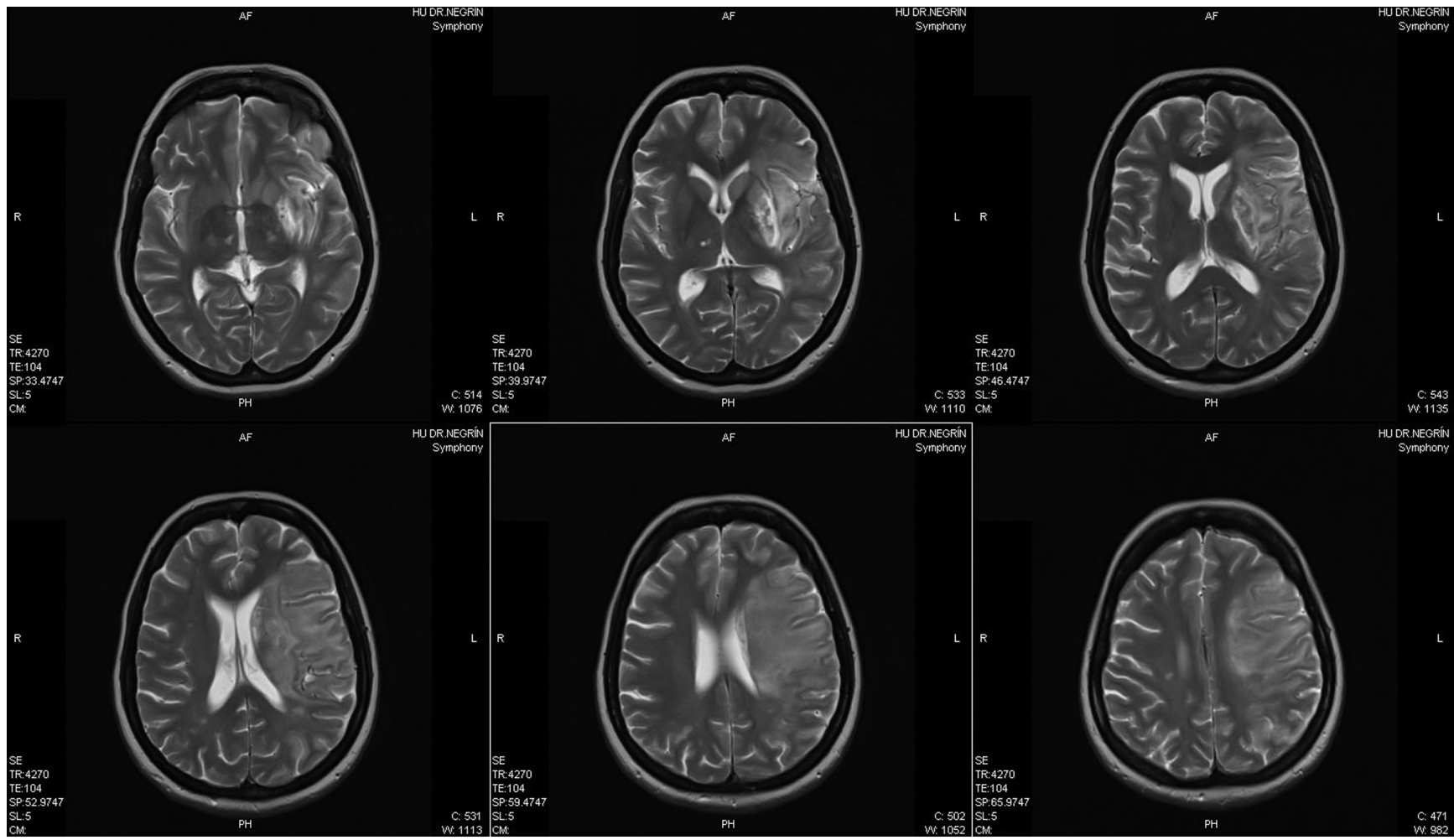

Figure: T2-weighted magnetic resonance imaging showed a large hyperintense lesion within the territory of the left middle cerebral artery.

controlled trials and studies have documented its efficacy and safety ${ }^{6}$. The risk of cerebrovascular events in patients taking tranexamic acid could be higher in those with other prothrombotic factors, like patent oval foramen ${ }^{7}$ and oral contraceptives $^{8}$. Thus, it seems important not to maintain the treatment with tranexamic acid for a long period, especially if associated with other prothrombotic drugs, because it could increase the risk of ischemic stroke. No other causes of stroke were found in our patient after a broad diagnostic work-up that ruled out L-ICA dissection or other intra- or extracranial vessels abnormalities, cardiac source of emboli, inflammatory disease of the central nervous system, malignancy or inherited thrombophilia. Initial transcranial Doppler showed an asymmetric mean velocity profile in both MCAs, but intraarterial arteriography was normal, and no intracranial stenoses were detected.

In this case, we cannot confirm that treatment with tranexamic acid is the only etiological factor of ischemic stroke. However, we believe that tranexamic acid may have contributed to the condition as a prothrombotic factor associated with other risk factors previously described for ischemic stroke. Although ischemic strokes associated with tranexamic acid treatment are usually mild strokes with good functional prognosis 7,8 , they may less frequently may be severe strokes with adverse clinical implications ${ }^{9}$, as happened in our case. In conclusion, long-term tranexamic acid therapy should be avoided as far as possible, also avoiding its possible association with proth-rombotic conditions such as oral contraceptives.

\section{REFERENCES}

1. Bevan H, Sharma K, Bradley W. Stroke in young adults. Stroke. 1990;21:382-6.

2. Adams HP Jr, Butler MJ, Biller J, Toffol GJ. Nonhemorrhagic cerebral infarction in young adults. Arch Neurol. 1986;43:793-6.

3. Nencini P, Inzitari D, Baruffi MC, Fratiglioni L, Gagliardi R, Benvenuti L, et al. Incidence of stroke in young adults in Florence, Italy. Stroke. 1988:977-81

4. Bogousslavsky J, Regli F. Ischemic strokes in adults younger than 30 years of age: cause and prognosis. Arch Neurol. 1987;44: 479-82.

5. Chang CL, Donaghy M, Poulter N. Migraine and stroke in young women: case-control study. The World Health Organisation Collaborative Study of Cardiovascular Disease and Steroid Hormone Contraception. Brit Med J. 1999;318:13-8.

6. Bonnar J, Sheppard BL. Treatment of menorrhagia during menstruation: randomised controlled trial of ethamsylate, mefenamic acid, and tranexamic acid. Brit Med J. 1996;313: 579-82.

7. Jericó-Pascual I, Gállego-Culleré J. Ictus, ácido tranexámico y foramen oval permeable. Rev Neurol. 2008;46:186.

8. Idbaih A, Crassard I, Vahedi K, Guichard JP, Woimant F. Thrombotic cocktail in stroke. Neurology. 2005;64:334.

9. Agnelli G, Gresele P, De Cunto M, Gallai V, Nenci GG. Tranexamic acid, intrauterine contraceptive devices and fatal cerebral arterial thrombosis. Case report. Br J Obstet Gynaecol. 1982;89:681-2. 